\title{
Assessment of different methods for the detection of biofilm production in coagulase-negative staphylococci isolated from blood cultures of newborns
}

\author{
Roberta Filipini Rampelotto[1],[2], Vinicius Victor Lorenzoni ${ }^{[1]}$, Danielly da Costa Silva[1],[2], \\ Silvana Silveira Coelho ${ }^{[1]}$, Vanessa Wust ${ }^{[1]}$, Litiérri Razia Garzon ${ }^{[1]}$, \\ Melise Silveira Nunes ${ }^{[1],[3]}$, Bettina Meneghetti ${ }^{[1],[3]}$, Patrícia Chaves Brites ${ }^{[4]}$, \\ Manfredo Hörner ${ }^{[5]}$ and Rosmari Hörner ${ }^{[1],[2]}$
}

\begin{abstract}
[1]. Departamento de Análises Clínicas, Universidade Federal de Santa Maria, Santa Maria, RS, Brasil. [2]. Programa de Pós-Graduação, Universidade Federal de Santa Maria, Santa Maria, RS, Brasil. [3]. Laboratório de Análises Clínicas, Hospital Universitário de Santa Maria, Santa Maria, RS, Brasil. [4]. Laboratório de Biologia Molecular, Hospital Universitário de Santa Maria, Santa Maria, RS, Brasil. [5]. Departamento de Química, Universidade Federal de Santa Maria, Santa Maria, RS, Brasil.
\end{abstract}

\begin{abstract}
Introduction: Coagulase-negative staphylococci (CoNS) are a frequent cause of bacteremia, especially in neonates. The major virulence determinant in CoNS is the ability to produce biofilms, which is conferred by the icaADBC genes. This study aimed to assess different methods for the detection of biofilm formation in 176 CoNS isolates from blood cultures of newborns. Methods: The presence of the icaACD genes was assessed by polymerase chain reaction (PCR), and biofilm formation was assessed on congo red agar (CRA), by the tube method (TM), and on tissue culture plates (TCP). Results: Of the 176 CoNS isolates, $30.1 \%$ expressed ica ACD and $11.4 \%$ expressed icaAD. The CRA assay and TM showed that $42 \%$ and $38.6 \%$ of the isolates were biofilm producing, respectively. On TCP, $40.9 \%$ of the isolates produced biofilms; $21 \%$ were weakly adherent and $19.9 \%$ were strongly adherent. When compared to the gold standard technique (PCR), the CRAassay showed $79 \%$ sensitivity and $84 \%$ specificity (kappa $=0.64)$, TM showed $78 \%$ sensitivity and $89 \%$ specificity $(\mathrm{kappa}=0.68)$, and TCP showed $99 \%$ sensitivity and $100 \%$ specificity (kappa $=0.99$ ). Conclusions: In this study, $\sim 42 \%$ of CoNS isolates produced biofilms, and the presence of ica ACD was associated with a greater capacity to form biofilms. Compared to the other phenotypic methodologies, TCP is an ideal procedure for routine laboratory use.
\end{abstract}

Keywords: Biofilm. Blood culture. Coagulase-negative staphylococci. Newborn.

\section{INTRODUCTION}

Infections during the neonatal period lead to high levels of morbimortality.Sepsis is one of the most relevant complications of neonatal infections, and it increases the hospital care required for newborn babies ${ }^{1-3}$. Coagulase-negative staphylococci (CoNS), which are part of the normal skin microbiota, are the most frequently isolated pathogens in blood stream infections. In particular, Staphylococcus epidermidis is capable of causing infections in both immunocompromised patients and newborns ${ }^{4-8}$.

CoNS infections are frequently associated with the use of invasive medical devices, and biofilm formation is a major

Corresponding author: Rosmari Hörner.

e-mail: rosmari.ufsm@gmail.com

Received 2 May 2018

Accepted 31 August 2018 virulence determinant in this group of bacteria ${ }^{4,7-11}$. The formation of biofilms allows these microorganisms to adhere to biomaterials, and biofilm formation is related to infection recurrence and therapy failure, as the organisms within biofilms are more resistant to antimicrobials and host defenses s,-9, $, 11,12^{\text {. }}$

In recent decades, there is increasing awareness of the great difficulty in eradicating infections caused by biofilm-forming bacteria, since these microorganisms are more resistant to and can survive in the presence of various antimicrobials, requiring removal of the related medical device or surgical methods to cure the infection ${ }^{6,12-15}$.

CoNS develop into biofilms via a complex, multifactorial process that can be divided into four phases: adhesion, accumulation, maturation, and detachment, each involving specific molecular factors ${ }^{8,13,16}$. Studies suggest that polysaccharide intercellular adhesin (PIA) is the most important component of Staphylococcus spp. biofilms. Biofilm production in Staphylococcus spp. is mediated by the chromosomal 
intracellular adhesion (ica) gene products, which are involved in cell adhesion and are arranged in an operon structure containing four biosynthesis genes ica $\mathrm{ABCD}^{7,11,13}$.

Considering the large number of infections caused by biofilm-forming bacteria, early detection and eradication of these microorganisms is necessary. A phenotypic method, along with detection of the genes in the ica operon, is generally used to verify biofilm production in Staphylococcus spp. infections ${ }^{7,12}$. The purpose of the present study was to assess four methods for the detection of biofilm production in CoNS isolates from blood cultures of newborn patients in a tertiary hospital in southern Brazil. The four methods evaluated were tissue culture plate (TCP), the tube method (TM), congo red agar (CRA), and polymerase chain reaction (PCR). This is the first study to assess biofilm production in CoNS isolates from blood cultures of newborn patients at this hospital.

\section{METHODS}

\section{Location and duration of study}

This study was conducted at the Laboratório de Bacteriologia, Departamento de Análises Clínicas e Toxicológicas, Centro de Ciências da Saúde of Universidade Federal de Santa Maria, Santa Maria, Rio Grande do Sul, Brazil. Samples were isolated at a tertiary hospital in southern Brazil during a one-year period (2014).

\section{Isolates}

One hundred and seventy-six (176) CoNS isolates were obtained from the blood cultures of newborns. Blood cultures were required whenever a significant clinical sign was present, such as increased body temperature $\left(>38^{\circ} \mathrm{C}\right)$, hypothermia $\left(<36^{\circ} \mathrm{C}\right)$, leukocytosis $\left(>10.000\right.$ leukocytes $/ \mathrm{mm}^{3}$, especially with left deviation), or absolute granulocytopenia $(<1000$ leukocytes/ $\mathrm{mm}^{3}$ ). For the cultures, a $3 \mathrm{~mL}$ sample of blood was collected from each newborn and placed in a blood culture bottle. At least two blood cultures were used for each sample. Isolates were processed with the BACTEC $9240 \AA$ automated blood culture system (Becton Dickson, Sparks, MD), and samples were considered positive when two or more blood cultures developed CoNS. Species-level identification of CoNS and antimicrobial sensitivity profiles were performed with the Vitek ${ }^{\circledR} 2$ system (bioMérieux, France). The sensitivity profiles were determined according to the Clinical and Laboratory Standard Institute (CLSI) guidelines ${ }^{17}$ at the time of the study.

Blood cultures in which CoNS growth was detected were subsequently sent to the Laboratório de Bacteriologia, Departamento de Análises Clínicas e Toxicologicas, Centro de Ciências da Saúde at UFSM, where they were inoculated on tryptone soya agar (TSA) and incubated at $35 \pm 2{ }^{\circ} \mathrm{C}$ for $18-24 \mathrm{~h}$. The colonies were stored in tryptone soya broth (TSB) containing $15 \%$ glycerol at $-80^{\circ} \mathrm{C}$ until biofilm detection.

PCR, TM, and CRA were performed in duplicate, and TCP was performed in quadruplicate. S. epidermidis American Type Culture Collection (ATCC) 12228 and Staphylococcus aureus ATCC 25923 (a strong biofilm producer) were used as the negative and positive controls, respectively.

\section{Biofilm detection by the genotypic method (PCR)}

DNA was extracted by the boiling method of Pérez-Pérez and Hanson ${ }^{18}$. The 16S rRNA gene sequence was determined to verify the presence of CoNS bacterial DNA, and then the ica ACD genes were detected by PCR, which is considered the gold standard for detecting biofilm formation ability ${ }^{14,19}$. The primers used, which are shown in Table 1, were obtained from GBT Oligos ${ }^{\circledR}$ and were designed based on the Staphylococcus epidermidis ica $\mathrm{ACD}$ sequence (GenBank accession number U43366.1). To amplify the icaACD genes, a Thermo Cycler (model 2720, Biosystems) was used and programmed with the following cycling conditions: an initial step at $94^{\circ} \mathrm{C}$ for 5 min followed by 50 cycles of $30 \mathrm{sec}$ each at $94^{\circ} \mathrm{C}, 55.5^{\circ} \mathrm{C}$, and $72^{\circ} \mathrm{C}$, with a final step at $72^{\circ} \mathrm{C}$ for $1 \mathrm{~min}$. Each PCR simplex reaction contained $17.05 \mu \mathrm{L}$ of ultrapure water, $1.75 \mu \mathrm{L}$ of buffer (10×; Ludwig-Biotec $\left.{ }^{\circledR}\right), 0.75 \mu \mathrm{L}$ of $\mathrm{MgCl}_{2}(50 \mathrm{mM}$; Ludwig-Biotec $\left.{ }^{\circledR}\right), 2 \mu \mathrm{L}$ of dNTPs (100 mM; Ludwig-Biotec $\AA$ ) s $0.2 \mu \mathrm{L}$ of Taq DNA polymerase (5U/mL; Ludwig-Biotec $($ ) $)$, $0.625 \mu \mathrm{L}$ of forward primer, $0.625 \mu \mathrm{L}$ of reverse primer, and $2 \mu \mathrm{L}$ of DNA. The DNA fragments were analyzed by $1.5 \%$

TABLE 1: Primers used for PCR.

\begin{tabular}{cccc}
\hline Gene & Primer & Sequence (5'-3') & Product size (bp) \\
\hline 16S rRNA & $16 \mathrm{~S}-\mathrm{F}$ & CCTATAAGACTGGGATAACTTCGGG & 791 \\
& $16 \mathrm{~S}-\mathrm{R}$ & CTTTGAGTTTCAACCTTGCGGTCG & ACAGTCGCTACGAAAAGAAA \\
$i c a \mathrm{~A}$ & $i c a \mathrm{~A}-\mathrm{F}$ & GGAAATGCCATAATGACAAC & 103 \\
& $i c a \mathrm{~A}-\mathrm{R}$ & TAACTTTAGGCGCATATGTTT & 400 \\
& $i c a \mathrm{C}-\mathrm{F}$ & TTCCAGTTAGGCTGGTATTG & 198 \\
& $i c a C-\mathrm{R}$ & ATGGTCAAGCCCAGACAGAG & CGTGTTTTCAACATTTAATGCAA
\end{tabular}


agarose gel electrophoresis, and the bands were visualized with a photo documentation system (KODAK DC 290, using 1D software, version 3.6).

\section{Biofilm detection by phenotypic methods Congo red agar (CRA)}

Isolates were analyzed according to the method described by Freeman et al. ${ }^{20}$. Briefly, isolates were inoculated on sheep blood agar, incubated at $35 \pm 2{ }^{\circ} \mathrm{C}$ for $24 \mathrm{~h}$, and then transferred to $\mathrm{CRA}$ and incubated at $35 \pm 2{ }^{\circ} \mathrm{C}$ for $24 \mathrm{~h}$. Biofilm-producing isolates formed black colonies, whereas non-biofilm-producing isolates formed red colonies.

\section{Tube method (TM)}

Isolates were assessed by the TM as described by Christensen et al. ${ }^{21}$. They were inoculated on sheep blood agar and incubated at $35 \pm 2{ }^{\circ} \mathrm{C}$ for $24 \mathrm{~h}$. Then, selected colonies were inoculated into test tubes containing $2.0 \mathrm{~mL}$ of TSB and incubated at $35 \pm 2{ }^{\circ} \mathrm{C}$ for $48 \mathrm{~h}$. Later, the contents were removed with a pipette, and $1.0 \mathrm{~mL}$ of a $0.4 \%$ aqueous solution of trypan blue was added to each tube. The stain was removed with a pipette and after a 1 min incubation, the results were read by visual observation. If colored bacteria adhered to the tube wall, the isolate was considered to be a biofilm producer, whereas if no colored microorganisms adhered to the tube wall, the isolate was considered to be a non-biofilm producer.

\section{Tissue culture plate (TCP)}

Isolates were assessed by the TCP method as described by Christensen et al. $(1985)^{22}$, with some modifications. The bacteria were inoculated on sheep blood agar and incubated at $35 \pm 2{ }^{\circ} \mathrm{C}$ for $24 \mathrm{~h}$. Then, colonies were transferred to test tubes containing $2.0 \mathrm{ml}$ of TSB and incubated at $35 \pm 2^{\circ} \mathrm{C}$ for $24 \mathrm{~h}$.

Using multichannel pipettes, $200 \mu \mathrm{L}$ of TSB containing $1 \%$ glucose was added to each well of a 96-wellflat bottom polystyrene tissue plate. Then, a $200 \mu \mathrm{L}$ aliquot of the aforementioned bacterial suspension in TSB was added to each well; each isolate was inoculated into four parallel wells, and the plates were incubated at $35 \pm 2{ }^{\circ} \mathrm{C}$ for $24 \mathrm{~h}$. Then, the contents of each well were aspirated, and the wells were washed four times with $200 \mu \mathrm{L}$ of phosphate-buffered saline (PBS, pH 7.2). The wells were stained with $100 \mu \mathrm{L}$ of $2 \%$ crystal violet for 1 min.Then, the stain was aspirated, and wells were washed with distilled water. Plates were dried for $1 \mathrm{~h}$ at room temperature. The optical density (OD) at 570 nmwas then read with an Epoch $^{\mathrm{TM}}$ Multi-volume Spectrophotometer (Biotech) ${ }^{22}$.

Sterile TSB containing 1\% glucose, which underwent all procedures described above, without the addition of microorganisms, was included as a medium control. A cut-off value for the detection of biofilm formation was calculated as the standard deviation multiplied by three plus the OD of the medium control (cut-off value $=$ standard deviation $\times 3+$ average OD medium control) ${ }^{22}$.

Isolates were classified into three categories: non-adherent (OD less than or equal to the cut-off value,i.e., $\mathrm{OD} \leq 0.116$ ), weakly adherent $(\mathrm{OD}>0.116$ and $\leq 0.232)$, and strongly adherent (OD> 0.232).

\section{Statistical analysis}

Sensitivity and specificity were calculated based on comparison of the phenotypic methods and PCR, which is considered a gold standard. The Kappa index (k) was also calculated to verify agreement between the results obtained from the different methods ${ }^{7,23}$. Data were analyzed using the Statistical Package for Social Sciences (SPSS) 20.0 for Windows. A p value less than 0.05 was considered statistically significant, and a $95 \%$ confidence interval (CI) was used.

\section{Ethical approval}

This study was approved by the Research Ethics Committee of Universidade Federal de Santa Maria (registration number 38850614.4.0000.5346).

\section{RESULTS}

The 16S rRNA gene was amplified in all 176 CoNS isolates, and $41.5 \%(73 / 176)$ were positive for icaA, icaC, or $i c a \mathrm{D}$ by PCR; 30.1\% (53/176) carried icaACD, 11.4\% (20/176) carried $i c a \mathrm{AD}$, and none of the isolates expressed ica $\mathrm{A}, i c a \mathrm{C}$, or ica $\mathrm{D}$ alone (Figure 1).

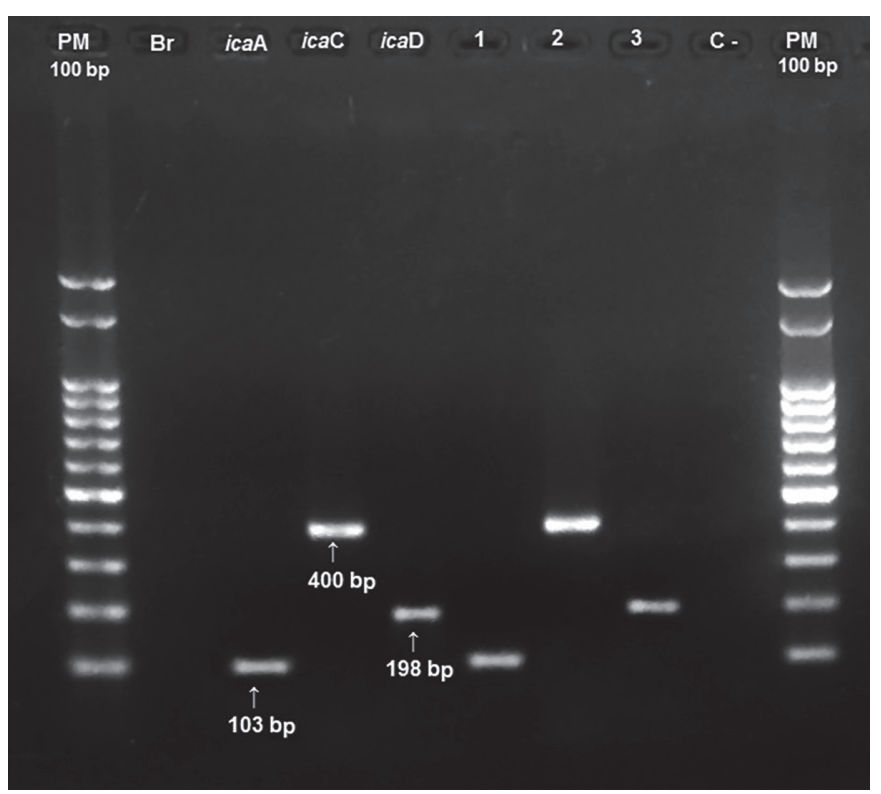

FIGURE 1: Presence of the icaA, icaC, and icaD genes in CoNS isolates from newborn blood cultures. $\mathrm{Br}=$ White; icaA = icaA-positive control; $i c a \mathrm{C}=i c a \mathrm{C}$-positive control; icaD = icaD positive control; $1=i c a \mathrm{~A}$-positive isolate; 2 = icaC-positive isolate; $3=i c a \mathrm{D}$-positive isolate; $\mathrm{C}$ - = Negative control (S. epidermidis ATCC 12228); PM 100bp = DNA ladder.

On CRA, 42\% (74/176) of the isolates showed black-colored colonies, indicative of biofilm production, and 58\% (102/176) showed red-colored colonies, indicating no biofilm production (Figure 2). The TM showed that 38.6\% (68/176) of isolates adhered to the tube walls and were considered positive for biofilm production, while $61.4 \%(108 / 176)$ of isolates did not adhere to the tube walls and were considered negative for biofilm production (Figure 3). In the TCP assay, 40.9\% (72/176) of 

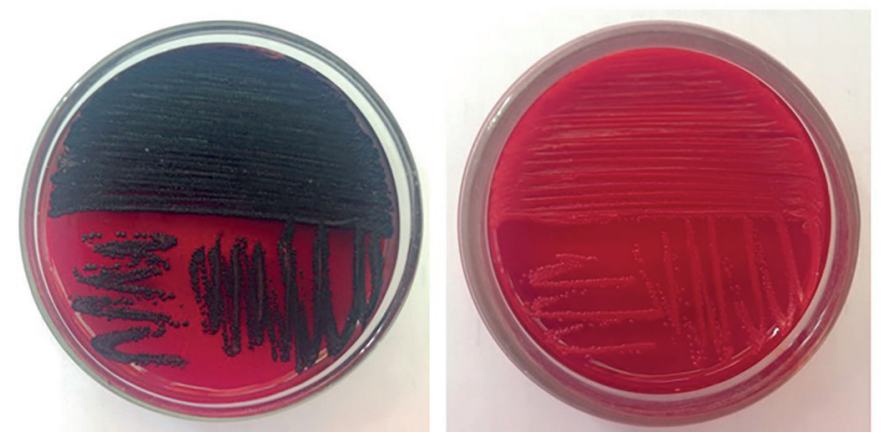

FIGURE 2: Biofilm production in CoNS isolates from newborn blood cultures as assessed by the congo red agar (CRA) assay. Left, a biofilm-producing isolate; right, a non-biofilm-producing isolate

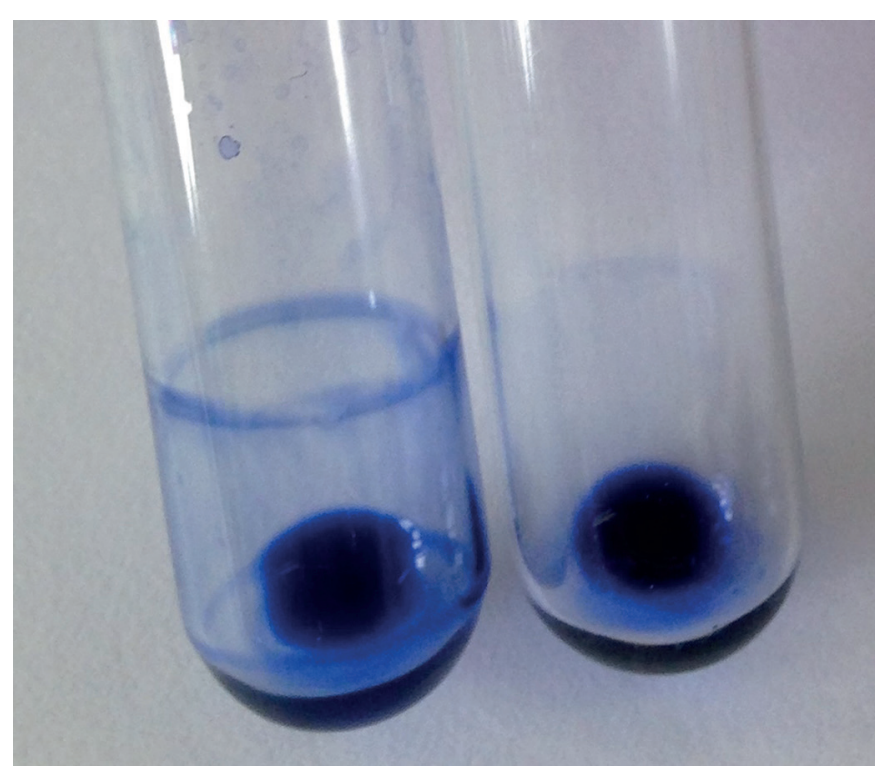

FIGURE 3: Biofilm production in CoNS isolates from newborn blood cultures as assessed by the tube method (TM). Left, a biofilm-producing isolate; right, a non-biofilm-producing isolate.

TABLE 2: Biofilm production in CoNS isolates from newborn blood cultures (n) as assessed by phenotypic techniques.

\begin{tabular}{lcccc}
\hline Species & PCR & CRA & TM & TCP \\
\hline S. epidermidis & 49 & 52 & 48 & 48 \\
S. warneri & 6 & 5 & 6 & 6 \\
S. capitis & 5 & 7 & 4 & 5 \\
S. haemolyticus & 4 & 3 & 3 & 4 \\
S. hominis & 3 & 2 & 2 & 3 \\
CoNS & 2 & 2 & 1 & 2 \\
S. lugdunensis & 1 & 1 & 1 & 1 \\
S. saprophyticus & 1 & 1 & 1 & 1 \\
S. xylosus & 1 & 1 & 1 & 1 \\
S. cohnii & 1 & - & 1 & 1 \\
\hline Total & 73 & 74 & 68 & 72 \\
\hline
\end{tabular}

PCR: polymerase chain reaction; CRA: congo red agar; TM: tube method; TCP: tissue culture plate; CoNS: coagulase-negative staphylococci. isolates produced biofilms; $21 \%$ (37/176) were weakly adherent, and $19.9 \%(35 / 176)$ were strongly adherent. Of the weakly adherent isolates, 78.4\% (29/37) expressed ica AD, and 21.6\% (8/37) expressed icaACD. All strongly adherent isolates (35/35) expressed all three genes (icaACD).

In our study, CRA showed $79 \%$ sensitivity ( $95 \%$ CI, 70-88), 84\% specificity (95\% CI, 76-92), 82\% accuracy, and good agreement (Kappa $=0.64)$; the TM assay showed $78 \%$ sensitivity (95\% CI, 69-87), 89\% specificity (95\% CI, $82-96$ ), and $85 \%$ accuracy, and good agreement (Kappa $=$ 0.83 ); and the TCP method showed $99 \%$ sensitivity ( $95 \%$ CI, 97-100), 100\% specificity (95\% CI, 99-100), 99\% accuracy, and excellent agreement $(\mathrm{Kappa}=0.99)$, when compared to the gold standard, PCR.

Among the isolates that were positive for ica $\mathrm{ACD}$ or ica $\mathrm{AD}$ by PCR, $S$. epidermidis was the prevalent species $(67.1 \%$, 49/73), followed by $S$. warneri $(8.2 \%, 6 / 73)$. Table 2 shows the number of biofilm-producing CoNS species that were positive by the four tested techniques (PCR, CRA, TM, and TCP). Table 3 shows the percentages of biofilm-producing and non-biofilm-producing isolates that were resistant to each tested antimicrobial. All isolates in this study were sensitive to linezolid, tigecycline, and vancomycin.

\section{DISCUSSION}

In this study, we analyzed the biofilm-formation ability of 176 CoNS isolates by four different techniques. Among the 176 isolates, $41.5 \%$ of were positive for $i c a \mathrm{~A}, i c a \mathrm{C}$, or $i c a \mathrm{D}$ by PCR; $30.1 \%$ expressed ica $\mathrm{ACD}$, and $11.4 \%$ expressed icaAD. Oliveira and $\mathrm{Cunha}^{7}$ compared different methods for detecting biofilm formation in CoNS isolates from clinical specimens of newborns and the nasal cavity of healthy people in Botucatu, São Paulo, Brazil. They found that $82 \%$ of isolates were positive for icaA, $i c a \mathrm{C}$, or $i c a \mathrm{D}$ by $\mathrm{PCR} ; 40 \%$ carried ica $\mathrm{AD}$, and $42 \%$ carried all three genes (icaACD). These percentages were higher than those in our study. Zalipour et al. ${ }^{12}$ also assessed this virulence determinant in Staphylococcus spp. obtained from different clinical specimens collected in two school hospitals in Iran, and also found a higher rate than that in our study, as $81.9 \%$ of the S. epidermidis isolates expressed ica $\mathrm{AD}$.

Regarding the phenotypic methods, $42 \%$ of the isolates showed biofilm production by the CRA assay. Similar results were reported by Öcal et al. ${ }^{11}$ for CoNS isolates in samples from nasal cavities, catheters, and blood cultures of patients admitted to a hospital in Turkey; $40.3 \%$ of isolates produced biofilms by the CRA technique. In contrast, Oliveira and $\mathrm{Cunha}^{7}$ and Zalipour et al. ${ }^{12}$ reported higher rates of biofilm formation on CRA, with $73 \%$ of CoNS and $70.8 \%$ of S. epidermidis, respectively. Hassan et al. ${ }^{24}$ assessed microorganisms isolated from different clinical materials in a hospital in Pakistan, and only $10 \%$ of the tested bacteria were biofilm producing using the CRA technique.

In this study, $38.6 \%$ of isolates were considered positive for biofilm formation by the TM. Hassan et al. ${ }^{24}$ and Oliveira and Cunha $^{7}$ found somewhat higher values using TM, with $\sim 49 \%$ and $82 \%$ biofilm-producing isolates, respectively. 
TABLE 3: Percentages of biofilm-forming and non-biofilm-forming* CoNS isolates from newborn blood cultures showing resistance to tested antimicrobials.

\begin{tabular}{|c|c|c|c|c|}
\hline Antimicrobials & $\mathbf{n}$ & $\begin{array}{c}\text { Resistant } \\
\text { biofilm producers } \\
n=73\end{array}$ & $\mathbf{n}$ & $\begin{array}{c}\text { Resistant } \\
\text { non-biofilm producers } \\
n=103\end{array}$ \\
\hline Ciprofloxacin & 51 & $69.9 \%$ & 41 & $39.8 \%$ \\
\hline Clindamycin & 30 & $41.1 \%$ & 10 & $9.7 \%$ \\
\hline Erythromycin & 44 & $60.3 \%$ & 42 & $40.8 \%$ \\
\hline Gentamicin & 45 & $61.6 \%$ & 41 & $39.8 \%$ \\
\hline Oxacillin & 71 & $97.3 \%$ & 62 & $60.2 \%$ \\
\hline Penicillin & 73 & $100 \%$ & 49 & $47.6 \%$ \\
\hline $\begin{array}{l}\text { Trimethoprim/ } \\
\text { Sulfamethoxazole }\end{array}$ & 41 & $54 \%$ & 31 & $30.1 \%$ \\
\hline
\end{tabular}

*Biofilm production was assessed with the gold standard technique (PCR).

Using TCP, $40.9 \%$ of our isolates were determined to be biofilm producing; $21 \%$ were weakly adherent, and $19.9 \%$ were strongly adherent. Oliveira and Cunha observed higher indices, and $81 \%$ of the isolates were biofilm producing by TCP; $35 \%$ were weakly adherent, and $46 \%$ were strongly adherent. Rani et al. ${ }^{25}$ assessed biofilm formation in S. epidermidis obtained from clinical specimens in a hospital in India using TCP, and all isolates produced biofilm. In contrast, Hassan et al. ${ }^{24}$ reported a value closer to that in our research, with $54.5 \%$ biofilm-producing isolates.

In the present study, of the weakly adherent isolates, $78.4 \%$ carried ica $\mathrm{AD}$ and $21.6 \%$ carried ica $\mathrm{ACD}$, whereas all the strongly adherent isolates carried all three genes. None carried one ica gene alone. Oliveira and $\mathrm{Cunha}^{7}$ reported that only $56.5 \%$ of the strongly adherent isolates contained all three genes (icaACD). These studies demonstrate that the presence of the icaACD genes is an important virulence determinant in clinical isolates of CoNS, since their expression is associated with the production of PIA, a major component of biofilms in Staphylococcus spp.? We assumed that the presence of only one of the genes in the ica operon is not sufficient for biofilm formation ${ }^{26}$.

The expression of icaA alone induces low enzymatic activity, as these strains typically produce only small amounts of PIA. The presence of $i c a \mathrm{D}$ favors the production of polysaccharide, and larger chains are synthesized in the presence of $i c a \mathrm{C}$. The expression of ica $\mathrm{AD}$ or icaACD stimulates increased biofilm production; whereas ica $\mathrm{B}$ appears to function as a deacetylase for the formation of $\mathrm{PIA}^{7,11,13,27}$. In addition to this ica operonrelated mechanism of biofilm formation, biofilms can also be formed through protein adhesion mediated by surface proteins, such as biofilm-associated protein (Bap), its homologs Bhp and accumulation associated protein (Aap), and extracellular matrix binding protein $(E m b p)$, via cell adhesion and accumulation ${ }^{28-30}$.

In our study, the CRA assay showed $79 \%$ sensitivity, $84 \%$ specificity, and $82 \%$ accuracy (kappa $=0.64$ ); the TM assay showed $78 \%$ sensitivity, $89 \%$ specificity, and $85 \%$ accuracy $($ kappa $=0.68)$; and the TCP assay showed 99\% sensitivity, $100 \%$ specificity, and 99\% accuracy (kappa $=0.99$ ), when compared to the gold standard, PCR. Oliveira and $\mathrm{Cunha}^{7}$ compared the three techniques used in our study (CRA, TM, and TCP) to the gold standard technique (PCR) for strains that carried the biofilm-producing genes icaACD. They observed $100 \%$ sensitivity and specificity for the TM, $89 \%$ sensitivity and $100 \%$ specificity for the CRA assay,and $96 \%$ sensitivity and $94 \%$ specificity for the TCP assay ${ }^{7}$. Thus, the authors concluded that the TM is the best method for biofilm detection due to its high sensitivity and specificity ${ }^{7}$. In our study, the CRA and TM assay failed to show consistent results. Thus, we concluded that TCP is the most suitable method for routine laboratory testing.

According to some researchers, the CRA assay is easier to implement than other methods; however, it is not recommended for biofilm detection in routine laboratory testing since it can yield false positive or false negative results ${ }^{7,31}$. In fact, a study conducted in India showed that the TM cannot be used as a general screening test to identify biofilm-producing strains ${ }^{32}$. However, Oliveira and Cunha ${ }^{7}$ recommended this qualitative method (TM) for biofilm research because it is a low cost method that yields reliable results. Although the TCP method is now considered the gold standard by some researchers ${ }^{24,25,32}$, as it is time-consuming, it is not widely used in routine laboratories ${ }^{7}$.

Among the biofilm-producing CoNS species detected by the standard technique (PCR), S. epidermidis was the most prevalent, at $67.1 \%$, followed by $S$. warneri (8.2\%). Oliveira and Cunha $^{7}$ reported $S$. epidermidis as the most prevalent species, which was present at a higher rate than in our study ${ }^{7}$. The fact that $S$. epidermidis shows the highest rate of biofilm production capacity may be due to special mechanisms, such as their ability to colonize the surface of medical devices, resilience, and because they colonize the skin of babies as soon as they are born. Furthermore, among CoNS, S. epidermidis is the species most frequently isolated from neonatal infections, and it is frequently detected in infections associated with invasive devices ${ }^{7,13,15,25}$.

In this study, high rates of resistance to penicillin, oxacillin, and clindamycin were detected among the biofilm-producing isolates. Research has shown that biofilm formation is associated with an increase in microbial resistance, and the acquisition of 
resistance characteristics via gene transfer is possible within biofilms ${ }^{33-35}$.

Our results showed that approximately $42 \%$ of CoNS isolates were positive for $i c a \mathrm{~A}, i c a \mathrm{C}$, or $i c a \mathrm{D}$ by $\mathrm{PCR}$, and strains containing all three genes (icaACD) showed a greater capacity to form biofilms. Regarding the phenotypic methodologies, the TM and CRA assay presented low of sensitivity and specificity values, and are not recommended for routine laboratory use. Thus, although the quantitative TCP method is a timeconsuming technique, it would be ideal for verifying biofilm production in nosocomial CoNS isolates.

This study has some limitations. First, even in the presence of ica genes, a strain may not form a biofilm in vitro due to non-expression of these genes. Conversely, some isolates may produce biofilm, even in the absence of the ica genes, which could interfere with the sensitivity and specificity. In addition, it is known that biofilm production can be induced via other icaindependent genes, such as Bap, Bhp, Aap, and Embp, which were not examined in this study.

\section{Acknowledgements}

We gratefully acknowledge the pharmaceutical staff of the Clinical Analysis Laboratory of the University Hospital of Santa Maria.

\section{Financial Support}

CAPES.

\section{Conflict of Interest}

The authors declare that there is no conflict of interest.

\section{REFERENCES}

1. Agarwal A, Bhat S. Clinico-microbiological study of neonatal sepsis. J Int Med Dentis. 2015;2(1):22-9.

2. Fjalstad JW, Stensvold HJ, Bergseng H, Simonsen GS, Salvesen B, Rønnestad AE, et al. Early-onset sepsis and antibiotic exposure in term infants: A nationwide population-based study in Norway. Pediatr Infect Dis J. 2016;35(1):1-6.

3. Oliveira MLA, Veronesi CL, Goulart LS. Caracterização de recémnascidos com hemoculturas positivas internados em Unidade de Terapia Intensiva neonatal. Rev Eletr G \& S. 2012;3(2):717-29.

4. Becker K, Heilmann C, Peters G. Coagulase-negative staphylococci. Clin Microbiol Rev. 2014;27(4):870-926.

5. Mitt P, Metsvaht T, Adamson V, Telling K, Naaber P, Lutsar I, et al. Five-year prospective surveillance of nosocomial bloodstream infections in an Estonian paediatric intensive care unit. J Hosp Infect. 2015;86(2):95-9.

6. Martínez-Meléndez A, Morfín-Otero R, Villarreal-Trevino L, Camacho-Ortíz A, González-González G, Llaca-Díaz J, et al. Molecular epidemiology of coagulase-negative bloodstream isolates: detection of Staphylococcus epidermidis ST2, ST7 and linezolid-resistant ST23. Braz J Infect Dis. 2016;20(5):419-28.

7. Oliveira A, Cunha MLRS. Comparasion of methods for the detection of biofilm production in coagulase-negative staphylococci. BMC Research Notes. 2010;3:260.
8. Pedroso SHSP, Sandes SHC, Luiz KCM, Dias RS, Filho RAT, Serufo $\mathrm{JC}$, et al. Biofilm and toxin profile: A phenotypic and genotypic characterization of coagulase-negative staphylococci isolated from human bloodstream infections. Microb Pathog. 2016;100:312-8.

9. Batistão DW, Campos PA, Camilo NC, Royer S, Araujo BF, Naves $\mathrm{KS}$, et al. Biofilm formation of Brazilian MRSA strains: prevalence of biofilm determinants and clonal profiles. J Med Microbiol. 2016;65:286-97.

10. Pinheiro L, Brito CI, De Oliveira A, Pereira VC, Da Cunha MLRS. Staphylococcus epidermidis and Staphylococcus haemolyticus: detection of biofilm genes and biofilm formation in blood culture isolates from patients in a Brazilian teaching hospital. Diagn Microbiol Infect Dis. 2016;86(1):11-4.

11. Öcal DN, Dolapçı İ, Karahan ZC, Tekeli A. Investigation of biofilm formation properties of staphylococcus isolates. Mikrobiyol Bul. 2017;51(1):109.

12. Zalipour M, Ebrahim-Saraie HS, Sarvari J, Khashei R. Detection of biofilm production capability and icaA/D genes among staphylococci isolates from Shiraz, Iran. Jund J Microbiol. 2016;9(12):e41431.

13. Arciola CR, Campoccia D, Ravaioli S, Montanaro L. Polysaccharide intercellular adhesin in biofilm: structural and regulatory aspects. Front Cel Infect Microbiol. 2015; 1(5):1-10.

14. Solati SM, Tajbakhsh E, Khamesipour F, Gugnani HC. Prevalence of virulence genes of biofilm producing strains of Staphylococcus epidermidis isolated from clinical samples in Iran. AMB Express.2015;5:47.

15. Xu LC, Siedlecki CA. Submicron-textured biomaterial surface reduces staphylococcal bacterial adhesion and biofilm formation. Acta Biomater. 2012;8(1):72-81.

16. Otto M. Staphylococcal infections: mechanisms of biofilm maturation and detachment as critical determinants of pathogenicity. Annu Rev Med. 2013;64:175-188.

17. Clinical and Laboratory Standards Institute (CLSI). Performance Standards for Antimicrobial Susceptibility Testing; Nineteenth Informational Supplement Approved Standard M100-S24. CLSI, Wayne, Pensylvania, USA: CLSI, 2014.

18. Pérez-Pérez FJ, Hanson ND. Detection of plasmid-mediated AmpC $\beta$-lactamase genes in clinical isolates by using multiplex PCR. J Clin Microbiol; 2002;40(6):2153-62.

19. Arciola CR, Gamberini S, Campoccia D, Visai L, Speziale P, Baldassari L, et al. A multiplex PCR method for the detection of all five individual genes of ica locus in Staphylococcus epidermidis. A survey on 400 clinical isolates from prosthesis-associated infections. J Biomed Mater Res A. 2005;75:408-13.

20. Freeman DJ, Falkiner FR, Keane CT. New method for detecting slime production by coagulase negative staphylococci. J Clin Pathol. 1989;42:872-4.

21. Christensen GD, Simpson WA, Bisno AL, Beachey EH. Adherence of slime producing strains of Staphylococcus epidermidis to smooth surfaces. Infect Immun. 1982;37(1):318-26.

22. Christensen GD, Simpson WA, Younger JJ, Baddour LM, Barrett FF, Melton DM, et al. Adherence of coagulase-negative staphylococci to plastic tissue culture plates: a quantitative model for the adherence of staphylococci to medical devices. J Clin Microbiol. 1985;22(6):996-1006.

23. Vaz AJ, Takei K, Bueno EC. Imunoensaios: Fundamentos e Aplicações. Rio de Janeiro: Guanabara Koogau, 2007.

24. Hassan A, Usman J, Kaleem F, Omair M, Khalid A, Iqbal M. Evaluation of different detection methods of biofilm formation in the clinical isolates. Braz J Infect Dis. 2011; 15(4):305-11. 
25. Rani VS, Ravindra S, Rao RK. Biofilm detection and clinical significance of Staphylococcus epidermidis isolates. J Evol Med Dental Sciences. 2015;4(28):4844-9.

26. Fitzpatrick F, Humphreys H, O'Gara JP. Evidence for icaADBCindependent biofilm development mechanism in methicillinresistant Staphylococcus aureus clinical isolates. J Clin Microbiol. 2005;43(4):1973-6.

27. Otto M. Staphylococcal biofilms. Curr Top Microbiol Immunol. 2008;322:207-28.

28. Christner M, Franke GC, Schommer NN, Wendt U, Wegert K, Pehle P, et al. The giant extracellular matrix-binding protein of Staphylococcus epidermidis mediates biofilm accumulation and attachment to fibronectin. Mol Microbiol. 2010;75(1):187-207.

29. O'Gara JP. Ica and beyond: biofilm mechanisms and regulation in Staphylococcus epidermidis and Staphylococcus aureus. FEMS Microbiol Let. 2007;270(2):179-88.

30. Figueiredo AMS, Ferreira FA, Beltrame CO, Côrtes MF. The role of biofilms in persistent infections and factors involved in ica-independent biofilm development and gene regulation in Staphylococcus aureus. Crit Rev Microbiol. 2017;43(5):602-20.
31. Knobloch JK, Horstkotte MA, Rohde H, Mack D. Evaluation of different detection methods of biofilm formation in Staphylococcus aureus. Med Microbiol Immunol. 2002;191(2):101-6.

32. Mathur T, Singhal S, Khan S, Upadhyay DJ, Fatma T, Rattan A. Detection of biofilm formation among the clinical isolates of Staphylococci: An evaluation of three screening methods. Ind J Med Microbiol. 2006;24(1):25-9.

33. Haghighatpanah M, Mozaffari ASN, Mojtahedi A, Amirmozafari N, Zeighami H. Detection of extended-spectrum beta-lactamase (ESBL) and plasmid-borne blaCTX-M and blaTEM genes among clinical strains of Escherichia coli isolated from patients in the north of Iran. J Glob Antimicrob Resist.2016;7:110-3.

34. Subramanian P, Shanmugam N, Sivaraman U, Kumar S, Selvaraj $\mathrm{S}$. Antibiotic resistance pattern of biofilm-forming uropathogens isolated from catheterised patients in Pondicherry, India. Australas Med J. 2012;5(7):344-8.

35. De Araujo GL, Coelho LR, De Carvalho CB, Maciel RM, Coronado $\mathrm{AZ}$, Rozebaum R, et al. Commensal isolates of methicillinresistant Staphylococcus epidermidis are also well equipped to produce biofilm on polystyrene surfaces. J Antimicrob Chemother. 2006;57(5):855-64. 